\title{
On coupled coincidence point theorems on partially ordered $G$-metric spaces without mixed $g$-monotone
}

\author{
Phakdi Charoensawan* and Chaiporn Thangthong
}

*Correspondence:

phakdi@hotmail.com Department of Mathematics, Faculty of Science, Chiang Mai University, Chiang Mai, 50200, Thailand

\begin{abstract}
In this work, we prove the existence of a coupled coincidence point theorem of nonlinear contraction mappings in G-metric spaces without the mixed $g$-monotone property and give some examples of a nonlinear contraction mapping, which is not applied to the existence of coupled coincidence point by using the mixed monotone property. We also show the uniqueness of a coupled coincidence point of the given mapping. Further, we apply our results to the existence and uniqueness of a coupled coincidence point of the given mapping in partially ordered $G$-metric spaces.
\end{abstract}

Keywords: coupled fixed point; coupled coincidence point; invariant set; mixed g-monotone; partially ordered set; G-metric

\section{Introduction}

The existence of a fixed point for the contraction type of mappings in partially ordered metric spaces has been studied by Ran and Reurings [1] and they established some new results for contractions in partially ordered metric spaces and presented applications to matrix equations. Later, Nieto and Rodriguez-Lopez [2,3] and Agarwal et al. [4] presented some new results for contractions in partially ordered metric spaces. Examples of extensions and applications of these works see in [5-9].

The concept of coupled fixed point was introduced by Guo and Lakshmikantham [10]. Later, Bhaskar and Lakshmikantham [11] introduced the concept of mixed monotone property for contractive operators in partially ordered metric spaces. They also gave some applications in the existence and uniqueness of the coupled fixed point theorems for mappings which satisfy the mixed monotone property. Lakshimikantham and Cirić [12] extended the results in [11] by defining the mixed $g$-monotone and to study the existence and uniqueness of coupled coincidence point for such mapping which satisfy the mixed monotone property in partially ordered metric space. As a continuation of this work, many authors conducted research on the coupled fixed point theory and coupled coincidence point theory in partially ordered metric spaces and different spaces. For example see [13-47].

Recently, Sintunavarat et al. $[45,46]$ proved some coupled fixed point theorems for nonlinear contractions without mixed monotone property and extended some coupled fixed point theorems of Bhaskar and Lakshmikantham [11] by using the concept of $F$-invariant set due to Samet and Vetro [48]. Later, in 2013, Batra and Vashistha [19] introduced the

○2014Charoensawan and Thangthong; licensee Springer. This is an Open Access article distributed under the terms of the Creative Commons Attribution License (http://creativecommons.org/licenses/by/2.0), which permits unrestricted use, distribution, and reproduction in any medium, provided the original work is properly cited. 
concept of $(F, g)$-invariant set which is a generalization of an $F$-invariant set introduced by Samet and Vetro [48] and proved theorems on the existence of coupled fixed points for nonlinear contractions under $c$-distance in cone metric spaces having an $(F, g)$-invariant subset. Very recently, Charoensawan and Klanarong [25] proved theorems on the existence of coupled coincidence points in partially ordered metric spaces without mixed $g$-monotone property which extended some coupled fixed point theorems of Sintunavarat et al. [45]. They also proved uniqueness of coupled common fixed point theorems for nonlinear contractions.

In 2006, Mustafa and Sims [49] introduced the notion of a G-metric spaces as a generalization of the concept of a metric space and proved the analog of the Banach contraction mapping principle in the context of $G$-metric spaces. Following this initial research, many authors discussed research on the fixed point theory in partially ordered G-metric space (see, e.g., [50-66]).

Recently, Jleli and Samet [54] showed the weakness of the fixed point theory in G-metric by introducing the concept of a quasi-metric space and showed that the result of Mustafa $e t$ al. [57] can be deduced by some well-known results in the literature in the setting of a usual (quasi) metric space. Later, Samet et al. [63] established some propositions to show that many fixed point theorems on (nonsymmetric) $G$-metric spaces given recently by many authors follow directly from well-known theorems on metric spaces. However, Karapinar and Agarwal [55] noticed that the techniques used in [54, 63] are valid if the contraction condition in the statement of the theorem can be expressed in two variables and they proved some theorems on the existence and uniqueness of a common fixed point for which the techniques of the papers $[54,63]$ are not applicable.

In recent times, coupled fixed point and coupled coincidence point theory has been developed in partially ordered G-metric space. Some authors have studied coupled fixed point theory. For example, Choudhury and Maity [27] proved the existence of a coupled fixed point theorem of nonlinear contraction mappings with mixed monotone property in partially ordered G-metric space. Later, Abbas et al. [13] extended the results of a coupled fixed point theorem for a mixed monotone mapping obtained by Choudhury and Maity [27].

On the other hand, some authors have studied coupled coincidence point theory in partially ordered G-metric space. In 2011, Aydi et al. [15] established coupled coincidence and coupled common fixed point results for a mixed $g$-monotone mapping satisfying nonlinear contractions in a partially ordered G-metric space. They generalized the results obtained by Choudhury and Maity [27]. Later, Karapinar et al. [34] extended the results of coupled coincidence and coupled common fixed point theorem for a mixed $g$ monotone mapping obtained by Aydi et al. [15]. As a continuation of this trend, many authors have studied coupled coincidence point and coupled common fixed point results for a mixed $g$-monotone mapping satisfying nonlinear contractions in a partially ordered G-metric space (see, for example, [16-18, 24, 26, 28, 34, 43, 44, 50, 66]). However, very recently, Agarwal and Karapinar [50] introduced the concept of $g$-ordered completeness and showed that the weaknesses of some of the coupled fixed point theorems and coupled coincidence point theorems in $[13,15,26,27,43,67]$ are in fact immediate consequences of well-known fixed point theorems in the literature. 
In this work, we generalize and extend the coupled coincidence point theorem of nonlinear contraction mappings in partially ordered $G$-metric spaces without the mixed $g$-monotone property.

\section{Preliminaries}

In this section, we give some definitions, proposition, examples, and remarks which are useful for the main results in this paper. Throughout this paper, $(X, \leq)$ denotes a partially ordered set with the partial order $\leq$. By $x \leq y$, we mean $y \geq x$. A mapping $f: X \rightarrow X$ is said to be non-decreasing (resp., non-increasing) if, for all $x, y \in X, x \leq y$ implies $f(x) \leq f(y)$ (resp. $f(y) \geq f(x)$ ).

Definition 2.1 [49] Let $X$ be a nonempty set, and $G: X \times X \times X \rightarrow \mathbb{R}^{+}$be a function satisfying the following properties:

(G1) $G(x, y, z)=0$ if $x=y=z$.

(G2) $0<G(x, x, y)$ for all $x, y \in X$ with $x \neq y$.

(G3) $G(x, x, y) \leq G(x, y, z)$ for all $x, y, z \in X$ with $y \neq z$.

(G4) $G(x, y, z)=G(x, z, y)=G(y, z, x)=\cdots$ (symmetry in all three variables).

(G5) $G(x, y, z) \leq G(x, a, a)+G(a, y, z)$ for all $x, y, z, a \in X$ (rectangle inequality).

Then the function $G$ is called a generalized metric, or, more specially, a $G$-metric on $X$, and the pair $(X, G)$ is called a $G$-metric space.

Example 2.2 Let $(X, d)$ be a metric space. The function $G: X \times X \times X \rightarrow[0,+\infty)$, defined by $G(x, y, z)=d(x, y)+d(y, z)+d(z, x)$, for all $x, y, z \in X$, is a $G$-metric space on $X$.

Definition 2.3 [49] Let $(X, G)$ be a $G$-metric space, and let $\left(x_{n}\right)$ be a sequence of points of $X$. We say that $\left(x_{n}\right)$ is $G$-convergent to $x \in X$ if $\lim _{n, m \rightarrow \infty} G\left(x, x_{n}, x_{m}\right)=0$, that is, for any $\varepsilon>0$, there exists $N \in \mathbb{N}$ such that $G\left(x, x_{n}, x_{m}\right)<\varepsilon$, for all $n, m \geq N$. We call $x$ the limit of the sequence and write $x_{n} \rightarrow x$ or $\lim _{n \rightarrow \infty} x_{n}=x$.

Proposition 2.4 [49] Let $(X, G)$ be a G-metric space; the following are equivalent.

(1) $\left(x_{n}\right)$ is G-convergent to $x$.

(2) $G\left(x_{n}, x_{n}, x\right) \rightarrow 0$ as $n \rightarrow+\infty$.

(3) $G\left(x_{n}, x, x\right) \rightarrow 0$ as $n \rightarrow+\infty$.

(4) $G\left(x_{n}, x_{m}, x\right) \rightarrow 0$ as $n, m \rightarrow+\infty$.

Definition 2.5 [49] Let $(X, G)$ be a $G$-metric space. A sequence $\left(x_{n}\right)$ is called a $G$-Cauchy sequence if, for any $\varepsilon>0$, there exists $N \in \mathbb{N}$ such that $G\left(x_{n}, x_{m}, x_{l}\right)<\varepsilon$, for all $n, m, l \geq N$. That is, $G\left(x_{n}, x_{m}, x_{l}\right) \rightarrow 0$ as $n, m, l \rightarrow+\infty$.

Proposition 2.6 [49] Let $(X, G)$ be a G-metric space, the following are equivalent:

(1) the sequence $\left(x_{n}\right)$ is G-Cauchy;

(2) for any $\varepsilon>0$, there exists $N \in \mathbb{N}$ such that $G\left(x_{n}, x_{m}, x_{m}\right)<\varepsilon$, for all $n, m \geq N$.

Proposition 2.7 [49] Let $(X, G)$ be a G-metric space. A mapping $f: X \rightarrow X$ is G-continuous at $x \in X$ if and only if it is G-sequentially continuous at $x$, that is, whenever $\left(x_{n}\right)$ is G-convergent to $x,\left(f\left(x_{n}\right)\right)$ is G-convergent to $f(x)$. 
Definition 2.8 [49] A G-metric space $(X, G)$ is called $G$-complete if every $G$-Cauchy sequence is $G$-convergent in $(X, G)$.

Definition 2.9 [27] Let $(X, G)$ be a $G$-metric space. A mapping $F: X \times X \rightarrow X$ is said to be continuous if for any two G-convergent sequences $\left(x_{n}\right)$ and $\left(y_{n}\right)$ converging to $x$ and $y$, respectively, $\left(F\left(x_{n}, y_{n}\right)\right)$ is $G$-convergent to $F(x, y)$.

The concept of a mixed monotone property and a coupled fixed point have been introduced by Bhaskar and Lakshmikantham in [11].

Definition 2.10 [11] Let $(X, \leq)$ be a partially ordered set and $F: X \times X \rightarrow X$. We say $F$ has the mixed monotone property if for any $x, y \in X$

$$
x_{1}, x_{2} \in X, \quad x_{1} \leq x_{2} \quad \text { implies } \quad F\left(x_{1}, y\right) \leq F\left(x_{2}, y\right)
$$

and

$$
y_{1}, y_{2} \in X, \quad y_{1} \leq y_{2} \quad \text { implies } \quad F\left(x, y_{1}\right) \geq F\left(x, y_{2}\right) .
$$

Definition 2.11 [11] An element $(x, y) \in X \times X$ is called a coupled fixed point of a mapping $F: X \times X \rightarrow X$ if $F(x, y)=x$ and $F(y, x)=y$.

Lakshmikantham and Ćirić in [12] introduced the concept of a mixed $g$-monotone mapping and a coupled coincidence point.

Definition 2.12 [12] Let $(X, \leq)$ be a partially ordered set and $F: X \times X \rightarrow X$ and $g: X \rightarrow X$. We say $F$ has the mixed $g$-monotone property if for any $x, y \in X$

$$
x_{1}, x_{2} \in X, \quad g\left(x_{1}\right) \leq g\left(x_{2}\right) \quad \text { implies } \quad F\left(x_{1}, y\right) \leq F\left(x_{2}, y\right)
$$

and

$$
y_{1}, y_{2} \in X, \quad g\left(y_{1}\right) \leq g\left(y_{2}\right) \quad \text { implies } \quad F\left(x, y_{1}\right) \geq F\left(x, y_{2}\right) .
$$

Definition 2.13 [12] An element $(x, y) \in X \times X$ is called a coupled coincidence point of a mapping $F: X \times X \rightarrow X$ and $g: X \rightarrow X$ if $F(x, y)=g(x)$ and $F(y, x)=g(y)$.

Definition 2.14 [12] Let $X$ be a nonempty set and $F: X \times X \rightarrow X$ and $g: X \rightarrow X$. We say $F$ and $g$ are commutative if $g(F(x, y))=F(g(x), g(y))$ for all $x, y \in X$.

Now, we give the notion of an $F^{*}$-invariant set and an $\left(F^{*}, g\right)$-invariant set which is useful for our main results.

Definition 2.15 Let $(X, d)$ be a metric space and $F: X \times X \rightarrow X$ be mapping. Let $M$ be a nonempty subset of $X^{6}$. We say that $M$ is an $F^{*}$-invariant subset of $X^{6}$ if and only if, for all $x, y, z, u, v, w \in X$,

1. $(x, u, y, v, z, w) \in M \Leftrightarrow(w, z, v, y, u, x) \in M$

2. $(x, u, y, v, z, w) \in M \Rightarrow(F(x, u), F(u, x), F(y, v), F(v, y), F(z, w), F(w, z)) \in M$. 
Definition 2.16 Let $(X, d)$ be a metric space and $F: X \times X \rightarrow X$ and $g: X \rightarrow X$ are given mapping. Let $M$ be a nonempty subset of $X^{6}$. We say that $M$ is an $\left(F^{*}, g\right)$-invariant subset of $X^{6}$ if and only if, for all $x, y, z, u, v, w \in X$,

1. $(x, u, y, v, z, w) \in M \Leftrightarrow(w, z, v, y, u, x) \in M$;

2. $\quad(g(x), g(u), g(y), g(v), g(z), g(w)) \in M \Rightarrow$ $(F(x, u), F(u, x), F(y, v), F(v, y), F(z, w), F(w, z)) \in M$.

Definition 2.17 Let $(X, d)$ be a metric space and $M$ be a subset of $X^{6}$. We say that $M$ satisfies the transitive property if and only if, for all $x, y, w, z, a, b, c, d, e, f \in X$,

$$
(x, y, w, z, a, b) \in M \quad \text { and } \quad(a, b, c, d, e, f) \in M \rightarrow(x, y, w, z, e, f) \in M .
$$

\section{Remark}

1. The set $M=X^{6}$ is trivially $\left(F^{*}, g\right)$-invariant, which satisfies the transitive property.

2. Every $F^{*}$-invariant set is $\left(F^{*}, I_{X}\right)$-invariant when $I_{X}$ denote identity map on $X$.

Example 2.18 Let $(X, \leq)$ be a partially ordered set and suppose there is a metric $d$ on $X$ such that $(X, d)$ is a complete metric space. Let $F: X \times X \rightarrow X$ and $g: X \rightarrow X$ be a mapping satisfying the mixed $g$-monotone property. Define a subset $M \subseteq X^{6}$ by $M=\left\{(a, b, c, d, e, f) \in X^{6}, a \geq c \geq e, b \leq d \leq f\right\}$. Then $M$ is an $\left(F^{*}, g\right)$-invariant subset of $X^{6}$, which satisfies the transitive property.

Example 2.19 Let $X=R$ and $F: X \times X \rightarrow X$ be defined by $F(x, y)=1-x^{2}$. Let $g: X \rightarrow X$ be given by $g(x)=x-1$. Then it is easy to show that $M=\left\{(x, 0,0,0,0, w) \in X^{6}: x=w\right\}$ is an $\left(F^{*}, g\right)$-invariant subset of $X^{6}$ but not an $F^{*}$-invariant subset of $X^{6}$ as $(1,0,0,0,0,1) \in M$ but $(F(1,0), F(0,1), F(0,0), F(0,0), F(0,1), F(1,0))=(0,1,1,1,1,0) \notin M$.

Let $\Phi$ denote the set of functions $\phi:[0, \infty) \rightarrow[0, \infty)$ satisfying

1. $\phi^{-1}(\{0\})=\{0\}$,

2. $\phi(t)<t$ for all $t>0$,

3. $\lim _{r \rightarrow t^{+}} \phi(r)<t$ for all $t>0$.

Lemma 2.20 [12] Let $\phi \in \Phi$. For all $t>0$, we have $\lim _{n \rightarrow \infty} \phi^{n}(t)=0$.

Karapinar et al. [34] proved the following theorem.

Theorem 2.21 [34] Let $(X, \leq)$ be a partially ordered set and $G$ be a G-metric on $X$ such that $(X, G)$ is a complete $G$-metric space. Suppose that there exist $\phi \in \Phi, F: X \times X \rightarrow X$, and $g: X \rightarrow X$ such that

$$
\begin{aligned}
& {[G(F(x, u), F(y, v), F(z, w))+G(F(u, x), F(v, y), F(w, z))]} \\
& \quad \leq \phi(G(g(x), g(y), g(z))+G(g(u), g(v), g(w)))
\end{aligned}
$$

for all $x, y, z, u, v, w \in X$ for which $g(x) \geq g(y) \geq g(z)$ and $g(u) \leq g(v) \leq g(w)$.

Suppose also that $F$ is continuous and has the mixed g-monotone property, $F(X \times X) \subseteq$ $G(X)$ and $g$ is continuous and commutes with $F$. If there exist $x_{0}, y_{0} \in X$ such that

$$
g\left(x_{0}\right) \leq F\left(x_{0}, y_{0}\right) \text { and } g\left(y_{0}\right) \geq F\left(y_{0}, x_{0}\right),
$$

then there exist $(x, y) \in X \times X$ such that $g(x)=F(x, y)$ and $g(y)=F(y, x)$. 
Definition 2.22 [34] Let $(X, \leq)$ be a partially ordered set and $G$ be a $G$-metric on $X$. We say that $(X, G, \leq)$ is regular if the following conditions hold:

1. if a non-decreasing sequence $\left(x_{n}\right) \rightarrow x$, then $x_{n} \leq x$ for all $n$,

2. if a non-increasing sequence $\left(y_{n}\right) \rightarrow y$, then $y \leq y_{n}$ for all $n$.

Theorem 2.23 [34] Let $(X, \leq)$ be a partially ordered set and $G$ be a G-metric on $X$ such that $(X, G, \leq)$ is regular. Suppose that there exist $\phi \in \Phi, F: X \times X \rightarrow X$, and $g: X \rightarrow X$ such that

$$
\begin{aligned}
& {[G(F(x, u), F(y, v), F(z, w))+G(F(u, x), F(v, y), F(w, z))]} \\
& \quad \leq \phi(G(g(x), g(y), g(z))+G(g(u), g(v), g(w)))
\end{aligned}
$$

for all $x, y, z, u, v, w \in X$ for which $g(x) \geq g(y) \geq g(z)$ and $g(u) \leq g(v) \leq g(w)$.

Suppose also that $(g(X), G)$ is complete, $F$ has the mixed $g$-monotone property, $F(X \times$ $X) \subseteq G(X)$, and $g$ is continuous and commutes with $F$. If there exist $x_{0}, y_{0} \in X$ such that

$$
g\left(x_{0}\right) \leq F\left(x_{0}, y_{0}\right) \text { and } g\left(y_{0}\right) \geq F\left(y_{0}, x_{0}\right)
$$

then there exist $(x, y) \in X \times X$ such that $g(x)=F(x, y)$ and $g(y)=F(y, x)$.

The purpose of this paper is to present some coupled coincidence point theorems without a mixed $g$-monotone, using the concept of $\left(F^{*}, g\right)$-invariant set in complete metric space which are generalizations of the results of Karapinar et al. [34].

\section{Main results}

Theorem 3.1 Let $(X, \leq)$ be a partially ordered set and $G$ be a $G$-metric on $X$ such that $(X, G)$ is a complete $G$-metric space and $M$ be a nonempty subset of $X^{6}$. Assume that there exists $\phi \in \Phi$ and, also, suppose that $F: X \times X \rightarrow X$ and $g: X \rightarrow X$ such that

$$
\begin{aligned}
& {[G(F(x, u), F(y, v), F(z, w))+G(F(u, x), F(v, y), F(w, z))]} \\
& \quad \leq \phi(G(g(x), g(y), g(z))+G(g(u), g(v), g(w)))
\end{aligned}
$$

for all $(g(x), g(u), g(y), g(v), g(z), g(w)) \in M$.

Suppose also that $F$ is continuous, $F(X \times X) \subseteq G(X)$ and $g$ is continuous and commutes with $F$. If there exist $x_{0}, y_{0} \in X \times X$ such that

$$
\left(F\left(x_{0}, y_{0}\right), F\left(y_{0}, x_{0}\right), F\left(x_{0}, y_{0}\right), F\left(y_{0}, x_{0}\right), g\left(x_{0}\right), g\left(y_{0}\right)\right) \in M
$$

and $M$ is an $\left(F^{*}, g\right)$-invariant set which satisfies the transitive property. Then there exist $x, y \in X$ such that $g(x)=F(x, y)$ and $g(y)=F(y, x)$.

Proof Let $\left(x_{0}, y_{0}\right) \in X \times X$. Since $F(X \times X) \subseteq g(X)$, we can choose $x_{1}, y_{1} \in X$ such that

$$
g\left(x_{1}\right)=F\left(x_{0}, y_{0}\right) \quad \text { and } \quad g\left(y_{1}\right)=F\left(y_{0}, x_{0}\right) .
$$

Again from $F(X \times X) \subseteq g(X)$ we can choose $x_{2}, y_{2} \in X$ such that

$$
g\left(x_{2}\right)=F\left(x_{1}, y_{1}\right) \quad \text { and } \quad g\left(y_{2}\right)=F\left(y_{1}, x_{1}\right) \text {. }
$$


Continuing this process we can construct sequences $\left\{g\left(x_{n}\right)\right\}$ and $\left\{g\left(y_{n}\right)\right\}$ in $X$ such that

$$
g\left(x_{n}\right)=F\left(x_{n-1}, y_{n-1}\right) \quad \text { and } \quad g\left(y_{n}\right)=F\left(y_{n-1}, x_{n-1}\right) \quad \text { for all } n \geq 1 .
$$

If there exists $k \in N$ such that $\left(g\left(x_{k+1}\right), g\left(y_{k+1}\right)\right)=\left(g\left(x_{k}\right), g\left(y_{k}\right)\right)$ then $g\left(x_{k}\right)=g\left(x_{k+1}\right)=$ $F\left(x_{k}, y_{k}\right)$ and $g\left(y_{k}\right)=g\left(y_{k+1}\right)=F\left(y_{k}, x_{k}\right)$. Thus, $\left(x_{k}, y_{k}\right)$ is a coupled coincidence point of $F$. The proof is completed.

Now we assume that $\left(g\left(x_{k+1}\right), g\left(y_{k+1}\right)\right) \neq\left(g\left(x_{k}\right), g\left(y_{k}\right)\right)$ for all $n \geq 0$. Thus, we have either $g\left(x_{n+1}\right)=F\left(x_{n}, y_{n}\right) \neq g\left(x_{n}\right)$ or $g\left(y_{n+1}\right)=F\left(y_{n}, x_{n}\right) \neq g(y)$ for all $n \geq 0$. Since

$$
\begin{aligned}
& \left(F\left(x_{0}, y_{0}\right), F\left(y_{0}, x_{0}\right), F\left(x_{0}, y_{0}\right), F\left(y_{0}, x_{0}\right), g\left(x_{0}\right), g\left(y_{0}\right)\right) \\
& \quad=\left(g\left(x_{1}\right), g\left(y_{1}\right), g\left(x_{1}\right), g\left(y_{1}\right), g\left(x_{0}\right), g\left(y_{0}\right)\right) \in M
\end{aligned}
$$

and $M$ is an $\left(F^{*}, g\right)$-invariant set, we have

$$
\begin{aligned}
& \left(F\left(x_{1}, y_{1}\right), F\left(y_{1}, x_{1}\right), F\left(x_{1}, y_{1}\right), F\left(y_{1}, x_{1}\right), F\left(x_{0}, y_{0}\right), F\left(y_{0}, x_{0}\right)\right) \\
& \quad=\left(g\left(x_{2}\right), g\left(y_{2}\right), g\left(x_{2}\right), g\left(y_{2}\right), g\left(x_{1}\right), g\left(y_{1}\right)\right) \in M .
\end{aligned}
$$

Again, using the fact that $M$ is an $\left(F^{*}, g\right)$-invariant set, we have

$$
\begin{aligned}
& \left(F\left(x_{2}, y_{2}\right), F\left(y_{2}, x_{2}\right), F\left(x_{2}, y_{2}\right), F\left(y_{2}, x_{2}\right), F\left(x_{1}, y_{1}\right), F\left(y_{1}, x_{1}\right)\right) \\
& \quad=\left(g\left(x_{3}\right), g\left(y_{3}\right), g\left(x_{3}\right), g\left(y_{3}\right), g\left(x_{2}\right), g\left(y_{2}\right)\right) \in M .
\end{aligned}
$$

By repeating this argument, we get

$$
\begin{aligned}
& \left(F\left(x_{n}, y_{n}\right), F\left(y_{n}, x_{n}\right), F\left(x_{n}, y_{n}\right), F\left(y_{n}, x_{n}\right), F\left(x_{n-1}, y_{n-1}\right), F\left(y_{n-1}, x_{n-1}\right)\right) \\
& \quad=\left(g\left(x_{n}\right), g\left(y_{n}\right), g\left(x_{n}\right), g\left(y_{n}\right), g\left(x_{n-1}\right), g\left(y_{n-1}\right)\right) \in M .
\end{aligned}
$$

From (1), (2), and (3), we have

$$
\begin{aligned}
& {\left[G\left(g\left(x_{n+1}\right), g\left(x_{n+1}\right), g\left(x_{n}\right)\right)+G\left(g\left(y_{n+1}\right), g\left(y_{n+1}\right), g\left(y_{n}\right)\right)\right]} \\
& =G\left(F\left(x_{n}, y_{n}\right), F\left(x_{n}, y_{n}\right), F\left(x_{n-1}, y_{n-1}\right)\right) \\
& \quad+G\left(F\left(y_{n}, x_{n}\right), F\left(y_{n}, x_{n}\right), F\left(y_{n-1}, x_{x-1}\right)\right) \\
& \leq \phi\left(G\left(g\left(x_{n}\right), g\left(x_{n}\right), g\left(x_{n-1}\right)\right)+G\left(g\left(y_{n}\right), g\left(y_{n}\right), g\left(y_{n-1}\right)\right)\right) .
\end{aligned}
$$

Let

$$
t_{n}=G\left(g\left(x_{n+1}\right), g\left(x_{n+1}\right), g\left(x_{n}\right)\right)+G\left(g\left(y_{n+1}\right), g\left(y_{n+1}\right), g\left(y_{n}\right)\right) .
$$

This implies that

$$
t_{n} \leq \phi\left(t_{n-1}\right)
$$

Since $\phi(t)<t$ for all $t>0$, it follows that $\left\{t_{n}\right\}$ is decreasing sequence. Therefore, there is some $\delta \geq 0$ such that $\lim _{n \rightarrow \infty} t_{n}=\delta$. 
We shall prove that $\delta=0$. Assume, to the contrary, that $\delta>0$. Then by letting $n \rightarrow \infty$ in (6) and using the properties of the map $\phi$, we get

$$
\delta=\lim _{n \rightarrow \infty} t_{n} \leq \lim _{n \rightarrow \infty} \phi\left(t_{n-1}\right)=\lim _{t_{n-1} \rightarrow \delta^{+}} \phi\left(t_{n-1}\right)<\delta .
$$

This is a contradiction. Thus $\delta=0$ and hence

$$
\lim _{n \rightarrow \infty} t_{n}=\lim _{n \rightarrow \infty}\left[G\left(g\left(x_{n+1}\right), g\left(x_{n+1}\right), g\left(x_{n}\right)\right)+G\left(g\left(y_{n+1}\right), g\left(y_{n+1}\right), g\left(y_{n}\right)\right)\right]=0 .
$$

Next, we prove that $\left\{g\left(x_{n}\right)\right\}$ and $\left\{g\left(y_{n}\right)\right\}$ are Cauchy sequences in the $G$-metric space $(X, G)$. Suppose, to the contrary, that the least of $\left\{g\left(x_{n}\right)\right\}$ and $\left\{g\left(y_{n}\right)\right\}$ is not a Cauchy sequence in $(X, G)$. Then there exists an $\varepsilon>0$ for which we can find subsequences $\left\{g\left(x_{m(k)}\right)\right\}$ and $\left\{g\left(x_{n(k)}\right)\right\}$ of $\left\{g\left(x_{n}\right)\right\},\left\{g\left(y_{m(k)}\right)\right\}$ and $\left\{g\left(y_{n(k)}\right)\right\}$ of $\left\{g\left(y_{n}\right)\right\}$ with $m(k)>n(k) \geq K$ such that

$$
G\left(g\left(x_{m(k)}\right), g\left(x_{m(k)}\right), g\left(x_{n(k)}\right)\right)+G\left(g\left(y_{m(k)}\right), g\left(y_{m(k)}\right), g\left(y_{n(k)}\right)\right) \geq \varepsilon .
$$

Further, corresponding to $n(k)$, we can choose $m(k)$ in such a way that it is the smallest integer with $m(k)>n(k) \geq K$ and satisfying (8). Then

$$
G\left(g\left(x_{m(k)-1}\right), g\left(x_{m(k)-1}\right), g\left(x_{n(k)}\right)\right)+G\left(g\left(y_{m(k)-1}\right), g\left(y_{m(k)-1}\right), g\left(y_{n(k)}\right)\right)<\varepsilon .
$$

Using the rectangle inequality, we get

$$
\begin{aligned}
\varepsilon \leq & r_{k} \\
:= & G\left(g\left(x_{m(k)}\right), g\left(x_{m(k)}\right), g\left(x_{n(k)}\right)\right)+G\left(g\left(y_{m(k)}\right), g\left(y_{m(k)}\right), g\left(y_{n(k)}\right)\right) \\
\leq & G\left(g\left(x_{m(k)}\right), g\left(x_{m(k)}\right), g\left(x_{m(k)-1}\right)\right)+G\left(g\left(x_{m(k)-1}\right), g\left(x_{m(k)-1}\right), g\left(x_{n(k)}\right)\right) \\
& +G\left(g\left(y_{m(k)}\right), g\left(y_{m(k)}\right), g\left(y_{m(k)-1}\right)\right)+G\left(g\left(y_{m(k)-1}\right), g\left(y_{m(k)-1}\right), g\left(y_{n(k)}\right)\right) \\
< & t_{m(k)-1}+\varepsilon .
\end{aligned}
$$

Letting $k \rightarrow+\infty$ and using (7), we get

$$
\lim _{k \rightarrow \infty} r_{k}=\lim _{k \rightarrow+\infty} G\left(g\left(x_{m(k)}\right), g\left(x_{m(k)}\right), g\left(x_{n(k)}\right)\right)+G\left(g\left(y_{m(k)}\right), g\left(y_{m(k)}\right), g\left(y_{n(k)}\right)\right)=\varepsilon
$$

Again, by the rectangle inequality, we have

$$
\begin{aligned}
r_{k}:= & G\left(g\left(x_{m(k)}\right), g\left(x_{m(k)}\right), g\left(x_{n(k)}\right)\right)+G\left(g\left(y_{m(k)}\right), g\left(y_{m(k)}\right), g\left(y_{n(k)}\right)\right) \\
\leq & t_{n(k)}+G\left(g\left(x_{m(k)}\right), g\left(x_{m(k)}\right), g\left(x_{m(k)+1}\right)\right) \\
& +G\left(g\left(x_{m(k)+1}\right), g\left(x_{m(k)+1}\right), g\left(x_{n(k)+1}\right)\right) \\
& +G\left(g\left(y_{m(k)}\right), g\left(y_{m(k)}\right), g\left(y_{m(k)+1}\right)\right)+G\left(g\left(y_{m(k)+1}\right), g\left(y_{m(k)+1}\right), g\left(y_{n(k)+1}\right)\right) .
\end{aligned}
$$

Using the fact that $G(x, x, y) \leq 2 G(x, y, y)$ for any $x, y \in X$, we obtain

$$
\begin{aligned}
r_{k} \leq & t_{n(k)}+2 t_{m(k)}+G\left(g\left(x_{m(k)+1}\right), g\left(x_{m(k)+1}\right), g\left(x_{n(k)+1}\right)\right) \\
+ & G\left(g\left(y_{m(k)+1}\right), g\left(y_{m(k)+1}\right), g\left(y_{n(k)+1}\right)\right) .
\end{aligned}
$$


Since $m(k)>n(k)$

$$
\left(g\left(x_{m(k)}\right), g\left(y_{m(k)}\right), g\left(x_{m(k)}\right), g\left(y_{m(k)}\right), g\left(x_{m(k)-1}\right), g\left(y_{m(k)-1}\right)\right) \in M
$$

and

$$
\left(g\left(x_{m(k)-1}\right), g\left(y_{m(k)-1}\right), g\left(x_{m(k)-1}\right), g\left(y_{m(k)-1}\right), g\left(x_{m(k)-2}\right), g\left(y_{m(k)-2}\right)\right) \in M
$$

From $M$ being an $\left(F^{*}, g\right)$-invariant set which satisfies the transitive property, we have

$$
\left(g\left(x_{m(k)}\right), g\left(y_{m(k)}\right), g\left(x_{m(k)}\right), g\left(y_{m(k)}\right), g\left(x_{m(k)-2}\right), g\left(y_{m(k)-2}\right)\right) \in M
$$

Again from

$$
\left(g\left(x_{m(k)-2}\right), g\left(y_{m(k)-2}\right), g\left(x_{m(k)-2}\right), g\left(y_{m(k)-2}\right), g\left(x_{m(k)-3}\right), g\left(y_{m(k)-3}\right)\right) \in M
$$

we get

$$
\left(g\left(x_{m(k)}\right), g\left(y_{m(k)}\right), g\left(x_{m(k)}\right), g\left(y_{m(k)}\right), g\left(x_{n(k)}\right), g\left(y_{n(k)}\right)\right) \in M \text {. }
$$

Now, using (1), we have

$$
\begin{aligned}
G( & \left.g\left(x_{m(k)+1}\right), g\left(x_{m(k)+1}\right), g\left(x_{n(k)+1}\right)\right)+G\left(g\left(y_{m(k)+1}\right), g\left(y_{m(k)+1}\right), g\left(y_{n(k)+1}\right)\right) \\
= & G\left(F\left(x_{m(k)}, y_{m(k)}\right), F\left(x_{m(k)}, y_{m(k)}\right), F\left(x_{n(k)}, y_{n(k)}\right)\right) \\
& \quad+G\left(F\left(y_{m(k)}, x_{m(k)}\right), F\left(y_{m(k)}, x_{m(k)}\right), F\left(y_{n(k)}, x_{n(k)}\right)\right) \\
\leq & \phi\left(G\left(g\left(x_{m(k)}\right), g\left(x_{m(k)}\right), g\left(x_{n(k)}\right)\right)+G\left(g\left(y_{m(k)}\right), g\left(y_{m(k)}\right), g\left(y_{n(k)}\right)\right)\right) \\
\leq & \phi\left(r_{k}\right) .
\end{aligned}
$$

Letting $k \rightarrow+\infty$ in (12) and using (7) and (11) and $\lim _{r \rightarrow t^{+}} \phi(r)<t$ for all $t>0$, we have

$$
\varepsilon=\lim _{k \rightarrow \infty} r_{k} \leq \lim _{n \rightarrow \infty} \phi\left(r_{k}\right)=\lim _{r_{k} \rightarrow \varepsilon^{+}} \phi\left(r_{k}\right)<\varepsilon
$$

This is a contradiction. This shows that $\left\{g\left(x_{n}\right)\right\}$ and $\left\{g\left(y_{n}\right)\right\}$ are Cauchy sequences in the $G$-metric space $(X, G)$. Since $(X, G)$ is complete, $\left\{g\left(x_{n}\right)\right\}$ and $\left\{g\left(y_{n}\right)\right\}$ are $G$-convergent; there exist $x, y \in X$ such that $\lim _{n \rightarrow \infty} g\left(x_{n}\right)=x$ and $\lim _{n \rightarrow \infty} g\left(y_{n}\right)=y$. That is, from Proposition 2.4, we have

$$
\begin{aligned}
& \lim _{n \rightarrow \infty} G\left(g\left(x_{n}\right), g\left(x_{n}\right), x\right)=\lim _{n \rightarrow \infty} G\left(g\left(x_{n}\right), x, x\right)=0, \\
& \lim _{n \rightarrow \infty} G\left(g\left(y_{n}\right), g\left(y_{n}\right), y\right)=\lim _{n \rightarrow \infty} G\left(g\left(y_{n}\right), y, y\right)=0 .
\end{aligned}
$$

From (13), (14), continuity of $g$, and Proposition 2.7, we get

$$
\begin{aligned}
& \lim _{n \rightarrow \infty} G\left(g\left(g\left(x_{n}\right)\right), g\left(g\left(x_{n}\right), g(x)\right)\right)=\lim _{n \rightarrow \infty} G\left(g\left(g\left(x_{n}\right)\right), g(x), g(x)\right)=0, \\
& \lim _{n \rightarrow \infty} G\left(g\left(g\left(y_{n}\right)\right), g\left(g\left(y_{n}\right)\right), g(y)\right)=\lim _{n \rightarrow \infty} G\left(g\left(g\left(y_{n}\right)\right), g(y), g(y)\right)=0 .
\end{aligned}
$$


From (2) and commutativity of $F$ and $g$,

$$
\begin{aligned}
& g\left(g\left(x_{n+1}\right)\right)=g\left(F\left(x_{n}, y_{n}\right)\right)=F\left(g\left(x_{n}\right), g\left(y_{n}\right)\right), \\
& g\left(g\left(y_{n+1}\right)\right)=g\left(F\left(y_{n}, x_{n}\right)\right)=F\left(g\left(y_{n}\right), g\left(x_{n}\right)\right) .
\end{aligned}
$$

We now show that $F(x, y)=g(x)$ and $F(y, x)=g(y)$.

Taking the limit as $n \rightarrow+\infty$ in (17) and (18), by (15), (16), continuity of $F$, and commutativity of $F$ and $g$, we get

$$
\begin{aligned}
g(x) & =g\left(\lim _{n \rightarrow \infty} g\left(x_{n+1}\right)\right)=\lim _{n \rightarrow \infty} g\left(g\left(x_{n+1}\right)\right)=\lim _{n \rightarrow \infty} g\left(F\left(x_{n}, y_{n}\right)\right) \\
& =\lim _{n \rightarrow \infty} F\left(g\left(x_{n}\right), g\left(y_{n}\right)\right)=F(x, y)
\end{aligned}
$$

and

$$
\begin{aligned}
g(y) & =g\left(\lim _{n \rightarrow \infty} g\left(x_{y+1}\right)\right)=\lim _{n \rightarrow \infty} g\left(g\left(y_{n+1}\right)\right)=\lim _{n \rightarrow \infty} g\left(F\left(y_{n}, x_{n}\right)\right) \\
& =\lim _{n \rightarrow \infty} F\left(g\left(y_{n}\right), g\left(x_{n}\right)\right)=F(y, x) .
\end{aligned}
$$

Thus we prove that $F(x, y)=g(x)$ and $F(y, x)=g(y)$.

Theorem 3.2 Let $(X, \leq)$ be a partially ordered set and $G$ be a G-metric on $X$ such that $(X, G)$ is a complete $G$-metric space and $M$ be a nonempty subset of $X^{6}$. Assume that there exists $\phi \in \Phi$ and, also, suppose that $F: X \times X \rightarrow X$ and $g: X \rightarrow X$ such that

$$
\begin{aligned}
& {[G(F(x, u), F(y, v), F(z, w))+G(F(u, x), F(v, y), F(w, z))]} \\
& \quad \leq \phi(G(g(x), g(y), g(z))+G(g(u), g(v), g(w)))
\end{aligned}
$$

for all $(g(x), g(u), g(y), g(v), g(z), g(w)) \in M$.

Suppose also that $(g(X), G)$ is complete $F(X \times X) \subseteq G(X)$ and $g$ is continuous and commutes with $F$ and if any two sequences $\left\{x_{n}\right\},\left\{y_{n}\right\}$ with $\left(x_{n+1}, y_{n+1}, x_{n+1}, y_{n+1}, x_{n}, y_{n}\right) \in M$, $\left\{x_{n}\right\} \rightarrow x$ and $\left\{y_{n}\right\} \rightarrow y$ for all $n \geq 1$, then $\left(x, y, x_{n}, y_{n}, x_{n}, y_{n}\right) \in M$. If there exist $\left(x_{0}, y_{0}\right) \in$ $X \times X$ such that $\left(F\left(x_{0}, y_{0}\right), F\left(y_{0}, x_{0}\right), F\left(x_{0}, y_{0}\right), F\left(y_{0}, x_{0}\right), g\left(x_{0}\right), g\left(y_{0}\right)\right) \in M$ and $M$ is an $\left(F^{*}, g\right)$ invariant set which satisfies the transitive property. Then there exist $x, y \in X$ such that $g(x)=F(x, y)$ and $g(y)=F(y, x)$.

Proof Consider a Cauchy sequences $\left\{g\left(x_{n}\right)\right\},\left\{g\left(y_{n}\right)\right\}$ as in the proof of Theorem 3.1. Since $(g(X), G)$ is a complete metric space, there exists $x, y \in X$ such that $\left\{g\left(x_{n}\right)\right\} \rightarrow g(x)$ and $\left\{g\left(y_{n}\right)\right\} \rightarrow g(y)$ by the assumption, and we have $\left(g(x), g(y), g\left(x_{n}\right), g\left(y_{n}\right), g\left(x_{n}\right), g\left(y_{n}\right)\right) \in M$ for all $n \geq 1$; by the rectangle inequality, (1), and $\phi(t)<t$ for all $t>0$, we get

$$
\begin{aligned}
& G(F(x, y), g(x), g(x))+G(F(y, x), g(y), g(y)) \\
& \leq \quad G\left(F(x, y), g\left(x_{n+1}\right), g\left(x_{n+1}\right)\right)+G\left(g\left(x_{n+1}\right), g(x), g(x)\right) \\
& \quad+G\left(F(y, x), g\left(y_{n+1}\right), g\left(y_{n+1}\right)\right)+G\left(g\left(y_{n+1}\right), g(y), g(y)\right) \\
& =G\left(F(x, y), F\left(x_{n}, y_{n}\right), F\left(x_{n}, y_{n}\right)\right)+G\left(g\left(x_{n+1}\right), g(x), g(x)\right)
\end{aligned}
$$




$$
\begin{aligned}
& +G\left(F(y, x), F\left(y_{n}, x_{n}\right), F\left(y_{n}, x_{n}\right)\right)+G\left(g\left(y_{n+1}\right), g(y), g(y)\right) \\
\leq & \phi\left(G\left(g(x), g\left(x_{n}\right), g\left(x_{n}\right)\right)+G\left(g(y), g\left(y_{n}\right), g\left(y_{n}\right)\right)\right) \\
& +G\left(g\left(x_{n+1}\right), g(x), g(x)\right)+G\left(g\left(y_{n+1}\right), g(y), g(y)\right) \\
< & G\left(g(x), g\left(x_{n}\right), g\left(x_{n}\right)\right)+G\left(g(y), g\left(y_{n}\right), g\left(y_{n}\right)\right) \\
\quad & +G\left(g\left(x_{n+1}\right), g(x), g(x)\right)+G\left(g\left(y_{n+1}\right), g(y), g(y)\right) .
\end{aligned}
$$

Taking the limit as $n \rightarrow \infty$ in the above inequality, we obtain

$$
G(F(x, y), g(x), g(x))+G(F(y, x), g(y), g(y))=0 .
$$

This implies that $g(x)=F(x, y)$ and $g(y)=F(y, x)$.

Example 3.3 Let $X=\mathbb{R}$. Define $G: X \times X \times X \rightarrow[0,+\infty)$ by $G(x, y, z)=|x-y|+|x-z|+$ $|y-z|$ and let $F: X \times X \rightarrow X$ be defined by

$$
F(x, y)=\frac{x+2 y}{4}, \quad(x, y) \in X^{2},
$$

and $g: X \rightarrow X$ by $g(x)=\frac{3 x}{2}$. Let $y_{1}=2$ and $y_{2}=4$. Then we have $g\left(y_{1}\right) \leq g\left(y_{2}\right)$, but $F\left(x, y_{1}\right) \leq$ $F\left(x, y_{2}\right)$, and so the mapping $F$ does not satisfy the mixed $g$-monotone property.

Letting $x, u, y, v, z, w \in X$, we have

$$
\begin{aligned}
& {[G(F(x, u), F(y, v), F(z, w))+G(F(u, x), F(v, u), F(w, z))]} \\
& =\left|\frac{x+2 u}{4}-\frac{y+2 v}{4}\right|+\left|\frac{x+2 u}{4}-\frac{z+2 w}{4}\right|+\left|\frac{y+2 v}{4}-\frac{z+2 w}{4}\right| \\
& \quad+\left|\frac{u+2 x}{4}-\frac{v+2 y}{4}\right|+\left|\frac{u+2 x}{4}-\frac{w+2 z}{4}\right|+\left|\frac{v+2 y}{4}-\frac{w+2 z}{4}\right| \\
& \leq 3\left|\frac{x-y}{4}\right|+3\left|\frac{x-z}{4}\right|+3\left|\frac{y-z}{4}\right|+3\left|\frac{u-v}{4}\right|+3\left|\frac{u-w}{4}\right|+3\left|\frac{v-w}{4}\right| \\
& =\frac{3}{4}(|x-y|+|x-z|+|y-z|)+\frac{3}{4}(|u-v|+|u-w|+|v-w|)
\end{aligned}
$$

and we have

$$
\begin{aligned}
& G(g(x), g(y), g(z))+G(g(u), g(v), g(w)) \\
& \quad=G\left(\frac{3 x}{2}, \frac{3 y}{2}, \frac{3 z}{2}\right)+G\left(\frac{3 u}{2}, \frac{3 v}{2}, \frac{3 w}{2}\right) \\
& \quad=\frac{3}{2}(|x-y|+|x-z|+|y-z|)+\frac{3}{2}(|u-v|+|u-w|+|v-w|) .
\end{aligned}
$$

Put $\phi(t)=t / 2$, then

$$
\begin{aligned}
& {[G(F(x, u), F(y, v), F(z, w))+G(F(u, x), F(v, u), F(w, z))]} \\
& \quad \leq \phi(G(g(x), g(y), g(z))+G(g(u), g(v), g(w))) .
\end{aligned}
$$


If we apply Theorem 3.1 with $M=X^{6}$ then $F$ satisfy (1). So by our theorem we see that $F$ has a coupled coincidence point $(0,0)$.

Remark Although the mixed monotone property is an essential tool in the partially ordered G-metric spaces to show the existence of coupled coincidence points, the mappings do not have the mixed $g$-monotone property in the general case as in the above example. Therefore, Theorem 3.1 and Theorem 3.2 are interesting, as a new auxiliary tool, in showing the existence of a coupled coincidence point.

Theorem 3.4 In addition to the hypotheses of Theorem 3.1, suppose that for every $(x, y),\left(x^{*}, y^{*}\right) \in X \times X$ there exist $(u, v) \in X \times X$ such that

$$
(g(u), g(v), g(x), g(y), g(x), g(y)) \in M \quad \text { and } \quad\left(g(u), g(v), g\left(x^{*}\right), g\left(y^{*}\right), g\left(x^{*}\right), g\left(y^{*}\right)\right) \in M .
$$

Suppose also that $\phi$ is a non-decreasing function. Then $F$ and $g$ have a unique coupled common fixed point, that is, there exist unique $(x, y) \in X \times X$ such that $x=g(x)=F(x, y)$ and $y=g(y)=F(y, x)$.

Proof From Theorem 3.1 the set of coupled coincidence point is nonempty. Suppose $(x, y)$ and $\left(x^{*}, y^{*}\right)$ are coupled coincidence point of $F$, that is,

$$
g(x)=F(x, y), \quad g(y)=F(y, x), \quad g\left(x^{*}\right)=F\left(x^{*}, y^{*}\right) \quad \text { and } \quad g\left(y^{*}\right)=F\left(y^{*}, x^{*}\right) .
$$

We shall show that

$$
g\left(x^{*}\right)=g(x) \text { and } \quad g\left(y^{*}\right)=g(y) .
$$

By assumption there is $(u, v) \in X \times X$ such that

$$
(g(u), g(v), g(x), g(y), g(x), g(y)) \in M \quad \text { and } \quad\left(g(u), g(v), g\left(x^{*}\right), g\left(y^{*}\right), g\left(x^{*}\right), g\left(y^{*}\right)\right) \in M \text {. }
$$

Put $u_{0}=u, v_{0}=v$ and choose $u_{1}, v_{1} \in X$ such that $g\left(u_{1}\right)=F\left(u_{0}, v_{0}\right)$ and $g\left(v_{1}\right)=F\left(v_{0}, u_{0}\right)$. Then similarly as in Theorem 3.1, we can inductively define sequences $\left\{g\left(u_{n}\right)\right\}$ and $\left\{g\left(v_{n}\right)\right\}$ such that

$$
g\left(u_{n}\right)=F\left(u_{n-1}, v_{n-1}\right) \quad \text { and } \quad g\left(v_{n}\right)=F\left(v_{n-1}, u_{n-1}\right) \quad \text { for all } n \geq 1 .
$$

Since $M$ is $\left(F^{*}, g\right)$-invariant and $\left(g\left(u_{0}\right), g\left(v_{0}\right), g(x), g(y), g(x), g(y)\right) \in M$, we have

$$
\left(F\left(u_{0}, v_{0}\right), F\left(v_{0}, u_{0}\right), F(x, y), F(y, x), F(x, y), F(y, x)\right) \in M .
$$

That is $\left(g\left(u_{1}\right), g\left(v_{1}\right), g(x), g(y), g(x), g(y)\right) \in M$.

From $\left(g\left(u_{1}\right), g\left(v_{1}\right), g(x), g(y), g(x), g(y)\right) \in M$, if we use again the property of $\left(F^{*}, g\right)$ invariance, then it follows that

$$
\left(F\left(u_{1}, v_{1}\right), F\left(v_{1}, u_{1}\right), F(x, y), F(y, x), F(x, y), F(y, x)\right) \in M
$$

and so $\left(g\left(u_{2}\right), g\left(v_{2}\right), g(x), g(y), g(x), g(y)\right) \in M$. 
By repeating this process, we get

$$
\left(g\left(u_{n}\right), g\left(v_{n}\right), g(x), g(y), g(x), g(y)\right) \in M \quad \text { for all } n \geq 1
$$

Thus from (1) and (20), we have

$$
\begin{aligned}
& G\left(g\left(u_{n+1}\right), g(x), g(x)\right)+G\left(g\left(v_{n+1}\right), g(y), g(y)\right) \\
& \quad=G\left(F\left(u_{n}, v_{n}\right), F(x, y), F(x, y)\right)+G\left(F\left(v_{n}, u_{n}\right), F(y, x), F(y, x)\right) \\
& \quad \leq \phi\left(G\left(g\left(u_{n}\right), g(x), g(x)\right)+G\left(g\left(v_{n}\right), g(y), g(y)\right)\right) .
\end{aligned}
$$

Since $\phi$ is non-decreasing from (21), we get

$$
\begin{aligned}
& G\left(g\left(u_{n+1}\right), g(x), g(x)\right)+G\left(g\left(v_{n+1}\right), g(y), g(y)\right) \\
& \quad \leq \phi^{n}\left(G\left(g\left(u_{1}\right), g(x), g(x)\right)+G\left(g\left(v_{1}\right), g(y), g(y)\right)\right) .
\end{aligned}
$$

This holds for each $n \geq 1$. Letting $n \rightarrow+\infty$ in (22), using Lemma 2.20 implies

$$
\lim _{n \rightarrow \infty} G\left(g\left(u_{n+1}\right), g(x), g(x)\right)=\lim _{n \rightarrow \infty} G\left(g\left(v_{n+1}\right), g(y), g(y)\right)=0 .
$$

Similarly, we obtain

$$
\lim _{n \rightarrow \infty} G\left(g\left(u_{n+1}\right), g\left(x^{*}\right), g\left(x^{*}\right)\right)=\lim _{n \rightarrow \infty} G\left(g\left(v_{n+1}\right), g\left(y^{*}\right), g\left(y^{*}\right)\right)=0 .
$$

Hence, from (23), (24), and Proposition 2.4, we get $g\left(x^{*}\right)=g(x)$ and $g\left(y^{*}\right)=g(y)$.

Since $g(x)=F(x, y)$ and $g(y)=F(y, x)$, by commutativity of $F$ and $g$, we have

$$
g(g(x))=g(F(x, y))=F(g(x), g(y)) \text { and } \quad g(g(y))=g(F(y, x))=F(g(y), g(x)) .
$$

Denote $g(x)=z$ and $g(y)=w$. Then from (25)

$$
g(z)=F(z, w) \text { and } \quad g(w)=F(w, z) .
$$

Therefore, $(z, w)$ is a coupled coincidence fixed point of $F$ and $g$. Then from (19) with $x^{*}=z$ and $y^{*}=w$, it follows that $g(z)=g(x)$ and $g(w)=g(y)$, that is,

$$
g(z)=z \quad \text { and } \quad g(w)=w
$$

From (26) and (27), $z=g(z)=F(z, w)$ and $w=g(w)=F(w, z)$. Therefore, $(z, w)$ is a coupled common fixed point of $F$ and $g$.

To prove the uniqueness, assume that $(p, q)$ is another coupled common fixed point. Then by (19) we have $p=g(p)=g(z)=z$ and $q=g(q)=g(w)=w$.

Next, we give a simple application of our results to coupled coincidence point theorems in partially ordered metric spaces. 
Corollary 3.5 Let $(X, \leq)$ be a partially ordered set and $G$ be a G-metric on $X$ such that $(X, G)$ is a complete G-metric space. Suppose that there exist $\phi \in \Phi, F: X \times X \rightarrow X$, and $g: X \rightarrow X$ such that

$$
\begin{aligned}
& {[G(F(x, u), F(y, v), F(z, w))+G(F(u, x), F(v, y), F(w, z))]} \\
& \quad \leq \phi(G(g(x), g(y), g(z))+G(g(u), g(v), g(w)))
\end{aligned}
$$

for all $x, y, z, u, v, w \in X$ for which $g(x) \geq g(y) \geq g(z)$ and $g(u) \leq g(v) \leq g(w)$.

Suppose also that $F$ is continuous and has the mixed g-monotone property, $F(X \times X) \subseteq$ $G(X)$ and $g$ is continuous and commutes with $F$. If there exist $x_{0}, y_{0} \in X$ such that

$$
g\left(x_{0}\right) \leq F\left(x_{0}, y_{0}\right) \text { and } g\left(y_{0}\right) \geq F\left(y_{0}, x_{0}\right) \text {, }
$$

then there exist $(x, y) \in X \times X$ such that $g(x)=F(x, y)$ and $g(y)=F(y, x)$.

Proof We define the subset $M \subseteq X^{6}$ by

$$
M=\left\{(x, u, y, v, z, w) \in X^{6}: x \geq y \geq z, u \leq v \leq w\right\} .
$$

From Example 2.18, $M$ is an $\left(F^{*}, g\right)$-invariant set which satisfies the transitive property. By (1), we have

$$
\begin{aligned}
& {[G(F(x, u), F(y, v), F(z, w))+G(F(u, x), F(v, y), F(w, z))]} \\
& \quad \leq \phi(G(g(x), g(y), g(z))+G(g(u), g(v), g(w))) .
\end{aligned}
$$

Since $x_{0}, y_{0} \in X$ such that

$$
g\left(x_{0}\right) \leq F\left(x_{0}, y_{0}\right) \quad \text { and } \quad g\left(y_{0}\right) \geq F\left(y_{0}, x_{0}\right) .
$$

We have $\left(F\left(x_{0}, y_{0}\right), F\left(y_{0}, x_{0}\right), F\left(x_{0}, y_{0}\right), F\left(y_{0}, x_{0}\right), g\left(x_{0}\right), g\left(y_{0}\right)\right) \in M$ because $F$ is continuous. By Theorem 3.1, we have $x=F(x, y)$ and $y=F(y, x)$.

Corollary 3.6 Let $(X, \leq)$ be a partially ordered set and $G$ be a G-metric on $X$ such that $(X, G, \leq)$ is regular. Suppose that there exists $\phi \in \Phi, F: X \times X \rightarrow X$ and $g: X \rightarrow X$ such that

$$
\begin{aligned}
& {[G(F(x, u), F(y, v), F(z, w))+G(F(u, x), F(v, u), F(w, z))]} \\
& \quad \leq \phi(G(g(x), g(y), g(z))+G(g(u), g(v), g(w)))
\end{aligned}
$$

for all $x, y, z, u, v, w \in X$ for which $g(x) \geq g(y) \geq g(z)$ and $g(u) \leq g(v) \leq g(w)$.

Suppose also that $(g(X), G)$ is complete, $F$ has the mixed $g$-monotone property, $F(X \times$ $X) \subseteq G(X)$, and $g$ is continuous and commutes with $F$. If there exist $x_{0}, y_{0} \in X$ such that

$$
g\left(x_{0}\right) \leq F\left(x_{0}, y_{0}\right) \text { and } g\left(y_{0}\right) \geq F\left(y_{0}, x_{0}\right)
$$

then there exist $(x, y) \in X \times X$ such that $g(x)=F(x, y)$ and $g(y)=F(y, x)$. 
Proof As in Corollary 3.5, we get

$$
\left(F\left(x_{0}, y_{0}\right), F\left(y_{0}, x_{0}\right), F\left(x_{0}, y_{0}\right), F\left(y_{0}, x_{0}\right), g\left(x_{0}\right), g\left(y_{0}\right)\right) \in M \text {. }
$$

For any two sequences $\left\{g\left(x_{n}\right)\right\},\left\{g\left(y_{n}\right)\right\}$ such that $\left\{g\left(x_{n}\right)\right\}$ is non-decreasing sequence $\left\{g\left(x_{n}\right)\right\} \rightarrow g(x)$ and $\left\{g\left(y_{n}\right)\right\}$ is non-increasing sequence $\left\{g\left(y_{n}\right)\right\} \rightarrow g(y)$. We have

$$
g\left(x_{1}\right) \leq g\left(x_{2}\right) \leq \cdots \leq g\left(x_{n}\right) \leq g(x)
$$

and

$$
g\left(y_{1}\right) \geq g\left(y_{2}\right) \geq \cdots \geq g\left(y_{n}\right) \geq g(y) \text { for all } n \geq 1 .
$$

Therefore, we have $\left(g(x), g(y), g\left(x_{n}\right), g\left(y_{n}\right), g\left(x_{n}\right), g\left(y_{n}\right)\right) \in M$ for all $n \geq 1$. So the assumption of Theorem 3.2 holds and hence $F$ has a coupled coincidence point.

Corollary 3.7 In addition to the hypothesis of Corollary 3.5, suppose that for every $(x, y),\left(x^{*}, y^{*}\right) \in X \times X$ there exists a $(u, v) \in X \times X$ such that $(F(u, v), F(v, u))$ is comparable to $(F(x, y), F(y, x))$ and $\left(F\left(x^{*}, y^{*}\right), F\left(y^{*}, x^{*}\right)\right)$. Suppose also that $\phi$ is a non-decreasing function. Then $F$ and $g$ have a unique coupled common fixed point, that is, there exists a unique $(x, y) \in X \times X$ such that $x=g(x)=F(x, y)$ and $y=g(y)=F(y, x)$.

Proof We define the subset $M \subseteq X^{6}$ by $M=\left\{(x, u, y, v, z, w) \in X^{6}: x \geq y \geq z, u \leq v \leq w\right\}$. From Example 2.18, $M$ is an $\left(F^{*}, g\right)$-invariant set which satisfies the transitive property. Thus, the proof of the existence of a coupled fixed point is straightforward by following the same lines as in the proof of Corollary 3.5.

Next, we show the uniqueness of a coupled fixed point of $F$.

Since for all $(x, y),\left(x^{*}, y^{*}\right) \in X \times X$, there exist $(u, v) \in X \times X$ such that $g(x) \leq g(u), g(y) \geq$ $g(v)$ and $g\left(x^{*}\right) \leq g(u), g\left(y^{*}\right) \geq g(v)$, we can conclude that

$$
(g(u), g(v), g(x), g(y), g(x), g(y)) \in M
$$

and

$$
\left(g(u), g(v), g\left(x^{*}\right), g\left(y^{*}\right), g\left(x^{*}\right), g\left(y^{*}\right)\right) \in M \text {. }
$$

Therefore, since all the hypotheses of Theorem 3.4 hold $F$ has a unique coupled fixed point. The proof is completed.

Competing interests

The authors declare that they have no competing interests.

Authors' contributions

The authors read and approved the final manuscript.

\section{Acknowledgements}

This research was supported by Chiang Mai University and the authors would like to express sincere gratitude to Prof Suthep Suantai and the referees for being kind enough to give very helpful suggestions and make many comments. 


\section{References}

1. Ran, A, Reurings, M: A fixed point theorem in partially ordered sets and some applications to matrix equations. Proc. Am. Math. Soc. 132, 1435-1443 (2004)

2. Nieto, JJ, Rodriguez-Lopez, R: Contractive mapping theorems in partially ordered sets and applications to ordinary differential equation. Order 22, 223-239 (2005)

3. Nieto, JJ, Rodriguez-Lopez, R: Existence and uniqueness of fixed point in partially ordered sets and applications to ordinary differential equation. Acta Math. Sin. Engl. Ser. 23(12), 2205-2212 (2007)

4. Agarwal, RP, El-Gebeily, MA, O'Regan, D: Generalized contractions in partially ordered metric spaces. Appl. Anal. 87 1-8 (2008)

5. Alghamdi, MA, Karapinar, E: G- $\beta-\psi$ Contractive type mappings and related fixed point theorems. J. Inequal. Appl. 2013, $70(2013)$

6. Aydi, H, Karapinar, E, Kumam, P: A note on 'Modified proof of Caristi's fixed point theorem on partial metric spaces, Journal of Inequalities and Applications 2013, 2013:210'. J. Inequal. Appl. 2013, 355 (2013). doi:10.1186/1029-242X-2013-355

7. Chaipunya, P, Sintunavarat, W, Kumam, P: On $\mathcal{P}$-contractions in ordered metric spaces. Fixed Point Theory Appl. 2012, 219 (2012). doi:10.1186/1687-1812-2012-219

8. Kumam, P, Vetro, C, Vetro, F: Fixed points for weak $\alpha$ - $\psi$-contractions in partial metric spaces. Abstr. Appl. Anal. 2013 Article ID 986028 (2013)

9. Sintunavarat, W, Kumam, P: Some fixed point results for weakly isotone mappings in ordered Banach spaces. Appl. Math. Comput. 224(1), 826-834 (2013)

10. Guo, D, Lakshmikantham, V: Coupled fixed points of nonlinear operators with applications. Nonlinear Anal. 11 , 623-632 (1987)

11. Bhaskar, TG, Lakshmikantham, V: Fixed point theorems in partially ordered metric spaces and applications. Nonlinear Anal. TMA 65, 1379-1393 (2006)

12. Lakshmikantham, V, Ćirić, L: Coupled fixed point theorems for nonlinear contractions in partially ordered metric spaces. Nonlinear Anal. TMA 70, 4341-4349 (2009)

13. Abbas, M, Sintunavarat, W, Kumam, P: Coupled fixed point of generalized contractive mappings on partially ordered G-metric spaces. Fixed Point Theory Appl. 2012, 31 (2012)

14. Amini-Harandi, A: Coupled and tripled fixed point theory in partially ordered metric spaces with application to initial value problem. Math. Comput. Model. 57(9-10), 2343-2348 (2013)

15. Aydi, H, Damjanović, B, Samet, B, Shatanawi, W: Coupled fixed point theorems for nonlinear contractions in partially ordered G-metric spaces. Math. Comput. Model. 54, 2443-2450 (2011)

16. Aydi, $H$, Postolache, $M$, Shatanawi, W: Coupled fixed point results for $(\psi, \varphi)$-weakly contractive mappings in ordered G-metric spaces. Comput. Math. Appl. 63(1), 298-309 (2012)

17. Aydi, H, Karapinar, E, Shatanawi, W: Tripled fixed point results in generalized metric spaces. J. Appl. Math. 2012, Article ID $314279(2012)$

18. Aydi, H, Karapinar, E, Shatanawi, W: Tripled common fixed point results for generalized contractions in ordered generalized metric spaces. Fixed Point Theory Appl. 2012, 101 (2012)

19. Batra, R, Vashistha, S: Coupled coincidence point theorems for nonlinear contractions under $(F, g)$-invariant set in cone metric spaces. J. Nonlinear Sci. Appl. 6, 86-96 (2013)

20. Berinde, $\vee$ : Generalized coupled fixed point theorems for mixed monotone mappings in partially ordered metric spaces. Nonlinear Anal. 74, 7347-7355 (2011)

21. Berinde, $\mathrm{V}$ : Coupled coincidence point theorems for mixed monotone nonlinear operators. Comput. Math. Appl. 64(6), 1770-1777 (2012)

22. Berinde, V: Coupled fixed point theorems for $\varphi$-contractive mixed monotone mappings in partially ordered metric spaces. Nonlinear Anal., Theory Methods Appl. 75(6), 3218-3228 (2012)

23. Berzig, M, Samet, B: An extension of coupled fixed point's concept in higher dimension and applications. Comput. Math. Appl. 63, 1319-1334 (2012)

24. Chandok, S, Sintunavarat, W, Kumam, P: Some coupled common fixed points for a pair of mappings in partially ordered G-metric spaces. Math. Sci. 7, 24 (2013). doi:10.1186/2251-7456-7-24

25. Charoensawan, $P$, Klanarong, C: Coupled coincidence point theorems for $\varphi$-contractive under $(f, g)$-invariant set in complete metric space. Int. J. Math. Anal. 7(33-36), 1685-1701 (2013)

26. Cho, YJ, Rhoades, BE, Saadati, R, Samet, B, Shatanawi, W: Nonlinear coupled fixed point theorems in ordered generalized metric spaces with integral type. Fixed Point Theory Appl. 2012, 8 (2012)

27. Choudhury, BS, Maity, P: Coupled fixed point results in generalized metric spaces. Math. Comput. Model. 54(1-2), 73-79 (2011)

28. Choudhury, BS, Kundu, A: A coupled coincidence point result in partially ordered metric spaces for compatible mappings. Nonlinear Anal. 73, 2524-2531 (2010)

29. Ding, H-S, Li, L: Coupled fixed point theorems in partially ordered cone metric spaces. Filomat 25(2), 137-149 (2011)

30. Hussain, N, Latif, A, Shah, MH: Coupled and tripled coincidence point results without compatibility. Fixed Point Theory Appl. 2012, 77 (2012)

31. Karapinar, E, Luong, NV, Thuan, NX, Hai, TT: Coupled coincidence points for mixed monotone operators in partially ordered metric spaces. Arab. J. Math. 1, 329-339 (2012)

32. Karapinar, E: Coupled fixed point theorems for nonlinear contractions in cone metric spaces. Comput. Math. Appl. 59 3656-3668 (2010)

33. Karapinar, E: Couple fixed point on cone metric spaces. Gazi Univ. J. Sci. 24, 51-58 (2011)

34. Karapinar, E, Kaymakcalan, B, Tas, K: On coupled fixed point theorems on partially ordered G-metric spaces. J. Inequal. Appl. 2012, 200 (2012)

35. Karapinar, E, Kumam, P, Erhan, I: Coupled fixed points on partially ordered G-metric spaces. Fixed Point Theory Appl. 2012, 174 (2012). doi:10.1186/1687-1812-2012-174

36. Karapinar, E, Roldan, A, Martinez-Moreno, J, Roldan, C: Meir-Keeler type multidimensional fixed point theorems in partially ordered metric spaces. Abstr. Appl. Anal. 2013, Article ID 406026 (2013) 
37. Kaushik, P, Kumar, S, Kumam, P: Coupled coincidence point theorems for $\alpha$ - $\psi$-contractive type mappings in partially ordered metric spaces. Fixed Point Theory Appl. 2013, 325 (2013). doi:10.1186/1687-1812-2013-325

38. Luong, NV, Thuan, NX: Coupled fixed points in partially ordered metric spaces and application. Nonlinear Anal. 74, 983-992 (2011)

39. Mursaleen, M, Mohiuddine, SA, Agarwal, RP: Coupled fixed point theorems for $\alpha$ - $\psi$-contractive type mappings in partially ordered metric spaces. Fixed Point Theory Appl. 2012, 228 (2012) (Corrigendum to Coupled fixed point theorems for $\alpha-\psi$-contractive type mappings in partially ordered metric spaces. Fixed Point Theory Appl. 2013, 127 (2013))

40. Roldan, A, Martinez-Moreno, J, Roldan, C: Multidimensional fixed point theorems in partially ordered complete metric spaces. J. Math. Anal. Appl. 396(2), 536-545 (2012)

41. Roldan, A, Martinez-Moreno, J, Roldan, C, Karapinar, E: Multidimensional fixed point theorems in partially ordered complete partial metric spaces under $(\psi, \varphi)$-contractivity conditions. Abstr. Appl. Anal. 2013, Article ID 634371 (2013)

42. Roldan, A, Karapinar, E: Some multidimensional fixed point theorems on partially preordered $G^{*}$-metric spaces under $(\psi, \varphi)$-contractivity conditions. Fixed Point Theory Appl. 2013, 158 (2013)

43. Shatanawi, W: Coupled fixed point theorems in generalized metric spaces. Hacet. J. Math. Stat. 40(3), 441-447 (2011)

44. Shatanawi, W, Abbas, M, Nazir, T: Common coupled coincidence and coupled fixed point results in two generalized metric spaces. Fixed Point Theory Appl. 2011, 80 (2011)

45. Sintunavarat, W, Kumam, P, Cho, YJ: Coupled fixed point theorems for nonlinear contractions without mixed monotone property. Fixed Point Theory Appl. 2012, 170 (2012)

46. Sintunavarat, W, Radenović, S, Golubović, Z, Kuman, P: Coupled fixed point theorems for F-invariant set. Appl. Math Inf. Sci. 7(1), 247-255 (2013)

47. Sintunavarat, W, Kumam, P: Coupled coincidence and coupled common fixed point theorems in partially ordered metric spaces. Thai J. Math. 10(3), 551-563 (2012)

48. Samet, B, Vetro, C: Coupled fixed point F-invariant set and fixed point of N-order. Ann. Funct. Anal. 1, 46-56 (2010)

49. Mustafa, Z, Sims, B: A new approach to generalized metric spaces. J. Nonlinear Convex Anal. 7(2), 289-297 (2006)

50. Agarwal, RP, Karapinar, E: Remarks on some coupled fixed point theorems in G-metric spaces. Fixed Point Theory Appl. 2013, 2 (2013)

51. Alghamdi, MA, Karapinar, E: G- $\beta-\psi$ Contractive type mappings in G-metric spaces. Fixed Point Theory Appl. 2013, 123 (2013)

52. Bilgili, N, Karapinar, E: Cyclic contractions via auxiliary functions on G-metric spaces. Fixed Point Theory Appl. 2013, 49 (2013)

53. Ding, H-S, Karapinar, E: Meir-Keeler type contractions in partially ordered G-metric space. Fixed Point Theory Appl. 2013, 35 (2013)

54. Jeli, M, Samet, B: Remarks on G-metric spaces and fixed point theorems. Fixed Point Theory Appl. 2012, 210 (2012)

55. Karapinar, E, Agarwal, RP: Further fixed point results on G-metric spaces. Fixed Point Theory Appl. 2013, 154 (2013)

56. Mustafa, Z, Aydi, H, Karapinar, E: On common fixed points in image-metric spaces using (E.A) property. Comput. Math. Appl. (2012). doi:10.1016/j.camwa.2012.03.051

57. Mustafa, Z, Obiedat, H, Awawdeh, F: Some fixed point theorem for mapping on complete G-metric spaces. Fixed Point Theory Appl. 2008, Article ID 189870 (2008)

58. Mustafa, Z, Khandaqji, M, Shatanawi, W: Fixed point results on complete G-metric spaces. Studia Sci. Math. Hung. 48, 304-319 (2011)

59. Mustafa, Z, Sims, B: Fixed point theorems for contractive mappings in complete G-metric spaces. Fixed Point Theory Appl. 2009, Article ID 917175 (2009)

60. Mustafa, Z, Shatanawi, W, Bataineh, M: Existence of fixed point results in G-metric spaces. Int. J. Math. Math. Sci. 2009, Article ID 283028 (2009)

61. Mustafa, Z, Aydi, H, Karapinar, E: Generalized Meir-Keeler type contractions on G-metric spaces. Appl. Math. Comput. 219(21), 10441-10447 (2013)

62. Roldan, A, Karapinar, E, Kumam, P: G-Metric spaces in any number of arguments and related fixed point theorems. Fixed Point Theory Appl. 2014, 13 (2014). doi:10.1186/1687-1812-2014-13

63. Samet, B, Vetro, C, Vetro, F: Remarks on G-metric spaces. Int. J. Anal. 2013, Article ID 917158 (2013)

64. Shatanawi, W: Fixed point theory for contractive mappings satisfying $\Phi$-maps in G-metric spaces. Fixed Point Theory Appl. 2010, Article ID 181650 (2010)

65. Shatanawi, W: Some fixed point theorems in ordered G-metric spaces and applications. Abstr. Appl. Anal. 2011, Article ID 126205 (2011)

66. Tahat, N, Aydi, H, Karapınar, E, Shatanawi, W: Common fixed points for single-valued and multi-valued maps satisfying a generalized contraction in G-metric spaces. Fixed Point Theory Appl. 2012, 48 (2012)

67. Nashine, HK: Coupled common fixed point results in ordered G-metric spaces. J. Nonlinear Sci. Appl. 1, 1-13 (2012)

10.1186/1029-242X-2014-150

Cite this article as: Charoensawan and Thangthong: On coupled coincidence point theorems on partially ordered

G-metric spaces without mixed g-monotone. Journal of Inequalities and Applications 2014, 2014:150 